\title{
COVID-19 Is Distinct From SARS-CoV-2-Negative Community-Acquired Pneumonia
}

\author{
Yutian Zhou ${ }^{1 \dagger}$, Shujin Guo ${ }^{1 \dagger}$, Ye He ${ }^{1 \dagger}$, Qiunan Zuo ${ }^{1}$, Danju Liu ${ }^{1}$, Meng Xiao ${ }^{1}$, Jinxiu Fan ${ }^{2 *}$ \\ and Xiaohui $\mathrm{Li}^{1 *}$ \\ ${ }^{1}$ The Geriatric Respiratory Department of Sichuan Provincial People's Hospital, University of Electronic Science and \\ Technology of China, Chengdu, China, ${ }^{2}$ The Respiratory Department of Wuhan Red Cross Hospital, Tongji Medical College \\ of Huazhong University of Science and Technology, Wuhan, China
}

Background: Corona virus disease (COVID-19) is an infectious respiratory disease that has spread rapidly across the world. Many studies have already evaluated the clinical features of COVID-19, but how it compares with severe acute respiratory syndrome coronavirus 2 (SARS-CoV-2)-negative community-acquired pneumonia (SN-CAP) is still unclear. Moreover, COVID-19 mortality is correlated with disease severity, but indicators for severity grading have not been specified. We aimed to analyze the clinical characteristics of COVID-19 in comparison with SN-CAP and find indicators for disease severity in COVID-19.

Methods: Patients diagnosed with COVID-19 and SN-CAP were enrolled. Clinical, radiological, and laboratory data were analyzed.

Results: The numbers of COVID-19 and SN-CAP patients enrolled were 304 and 138, respectively. The age of the patients was not significantly different between the groups. Compared with SN-CAP, COVID-19 patients had more symptoms of fever and dyspnea; and showed significant difference in blood count results. Computed tomography (CT) imaging of COVID-19 patients showed patchy ground-glass opacities that correlated with disease severity, whereas the CT imaging of SN-CAP patients showed patchy high-density shadows. COVID-19 patients were classified into moderate, severe, and critically severe groups. The severe and critically severe groups had elevated levels of white blood cells (WBC), neutrophils, platelets, C-reaction protein (CRP), lymphocyte ratio $(N L R)$, platelet to lymphocyte ratio $(P L R)$, troponin-I, creatinine, and blood urea nitrogen (BUN). However, they had decreased levels of lymphocytes, lymphocyte ratio, and albumin. Compared with the younger patients, the older COVID-19 individuals had more chronic diseases and significantly elevated levels of WBC, neutrophil, and CRP levels.

Conclusion: SN-CAP showed more inflammatory reaction than COVID-19. Old people with chronic diseases are more susceptible to COVID-19 and have a high likelihood of developing severe and critically severe infection. Levels of WBC, lymphocytes, neutrophils, CRP, NLR, PLR, troponin-I, creatinine, and BUN are important indicators for severity grading in COVID-19.

Keywords: COVID-19, clinical features, SARS-CoV-2, CAP, severity 


\section{INTRODUCTION}

In December 2019, pneumonia cases associated with a novel coronavirus were registered in Wuhan City, Hubei Province of China (World Health Organization, 2020b; Zhu et al., 2020). On February 11, 2020, the International Committee on Taxonomy of Viruses (ICTV) named the novel virus severe acute respiratory syndrome coronavirus 2 (SARS-CoV-2), while the World Health Organization (WHO) declared "coronavirus disease" (COVID19) as the official name of the disease caused by the virus. This followed an earlier declaration by the WHO on January 31, 2020, that had designated coronavirus disease a public health emergency of international concern. The Chinese governmentsponsored research activities to evaluate the genetic and clinical features of the infection provided comprehensive guidelines on disease epidemiology, etiology, diagnosis, treatment, nursing, and infection control for the hospital and community settings. However, the number of infections continued to increase exponentially, causing widespread fear and panic in the nation (Huang et al., 2020; Li et al., 2020; She et al., 2020). The disease started to spread from China to other nations, prompting the WHO, on February 28, 2020, to raise the alarm of COVID-19 being a very high-risk disease (Huang et al., 2020). As of April 29,2020 , the world had confirmed at least 3,250,000 COVID19 cases and 220,000 deaths, with both morbidity and mortality still rising.

The main pathogens for community-acquired pneumonia (CAP) are Streptococcus pneumoniae, Hemophilus influenzae, Mycoplasma pneumoniae, Chlamydophila legionella, virus (rhinovirus, adenovirus, coronavirus), and fungus (Metlay and Waterer, 2020). Unlike the common coronavirus, SARSCoV-2 is highly contagious. It is important to distinguish COVID-19 from other types of CAP. Few studies have compared the clinical features of COVID-19 and other pneumonia. One study enrolled 19 COVID-19 and 15 other pneumonia patients, but the results may lack reliability due to the small sample analyzed (Zhao et al., 2020); another study analyzed the respective CT imaging features (Shi et al., 2020). The differences between COVID-19 and SN-CAP are still unclear. Therefore, distinction analysis is urgently needed for clinicians.

According to the Chinese Center for Disease Control and Prevention (China CDC) (She et al., 2020), the mortality from COVID-19 in China stands at 2.3\%. Studies have shown that most patients have good prognosis, apart from older adults, who have fatal or near-fatal outcomes (Jin et al., 2020). Lymphopenia is an important symptom of COVID-19 (Huang et al., 2020); however, the indicators for disease severity grading are unclear. In this study, we aimed to analyze the clinical features of patients diagnosed with COVID-19 in Wuhan Red Cross Hospital and compare the clinical characteristics of COVID-19 to those of SN-CAP. Furthermore, we analyzed the clinical characteristics based on patient age, split into young age (18-44 years), middle age (45-59 years), and old age ( $\geq 60$ years), and identified indicators for severity grading in moderate, severe, and critically severe patients.

\section{MATERIALS AND METHODS}

\section{Patients}

In this retrospective study, cases diagnosed with COVID-19 according to WHO guidance (World Health Organization, 2020a) in Wuhan Red Cross Hospital from February 1, 2020, to March 15, 2020, and cases diagnosed with SN-CAP in Sichuan Provincial People's Hospital from February 1, 2020, to April 15, 2020, were enrolled. SN-CAP patients were negative for

TABLE 1 | Clinical characteristics of COVID-19 and SN-CAP.

\begin{tabular}{|c|c|c|c|}
\hline & $\begin{array}{l}\text { COVID-19 } \\
n=304\end{array}$ & $\begin{array}{l}\text { SN-CAP } \\
n=138\end{array}$ & $P$-value \\
\hline Age, mean (SD), y & $61.5(13.3 \%)$ & $61.6(16.1)$ & 0.921 \\
\hline Female & 166 (54.61\%) & $56(40.58 \%)$ & $<0.01$ \\
\hline Male & 138 (45.39\%) & $82(59.42 \%)$ & \\
\hline \multicolumn{4}{|c|}{ Signs and symptoms at admission, patient no } \\
\hline Fever & $172(56.58 \%)$ & $42(30.43)$ & $<0.01$ \\
\hline Cough & $134(44.08 \%)$ & $74(53.62)$ & 0.06 \\
\hline Dyspnea & $29(9.54 \%)$ & $3(2.17 \%)$ & $<0.01$ \\
\hline Fatigue & $32(10.53)$ & $5(3.62 \%)$ & 0.02 \\
\hline Chest distress & 24 (7.89\%) & $3(2.17 \%)$ & 0.02 \\
\hline Expectoration & 10 (3.29\%) & $53(38.41 \%)$ & $<0.01$ \\
\hline Sore throat & $5(1.64 \%)$ & $5(3.62 \%)$ & 0.2 \\
\hline Diarrhea & $5(1.64 \%)$ & $1(0.72 \%)$ & 0.4 \\
\hline Asymptomatic & 39 (12.83\%) & $6(4.35 \%)$ & $<0.01$ \\
\hline \multicolumn{4}{|c|}{ Chronic medical illness, patient no } \\
\hline Hypertension & $83(27.3 \%)$ & 34 (24.64\%) & 0.56 \\
\hline CAD & 21 (6.91\%) & $8(5.8 \%)$ & 0.66 \\
\hline Diabetes & $40(13.16 \%)$ & $25(18.12 \%)$ & 0.17 \\
\hline COPD & 7 (2.3\%) & $27(19.57 \%)$ & $<0.01$ \\
\hline Renal failure & $27(8.88 \%)$ & $18(13.04 \%)$ & 0.18 \\
\hline Malignancy & $3(0.99 \%)$ & $15(10.87 \%)$ & $<0.01$ \\
\hline \multicolumn{4}{|c|}{ Laboratory result abnormalities, patient no } \\
\hline $\begin{array}{l}\text { WBC count, }<3.7 \times \\
109 / L\end{array}$ & $42(13.82 \%)$ & $4(2.9 \%)$ & $<0.01$ \\
\hline $\begin{array}{l}\text { Lymphocyte count, <0.8 } \\
\times 109 / \text { L }\end{array}$ & $97(41.91 \%)$ & $68(49.28 \%)$ & $<0.01$ \\
\hline Lymphocyte ratio <20\% & $134(44.08 \%)$ & $93(67.39 \%)$ & $<0.01$ \\
\hline Neutrophil count, x109/L & $51(16.78 \%)$ & $37(26.81 \%)$ & 0.01 \\
\hline Platelet <85 × 109/L & 15 (4.93\%) & $7(5.07 \%)$ & 0.95 \\
\hline $\mathrm{CRP}>10 \mathrm{mg} / \mathrm{L}$ & $127(41.78 \%)$ & $98(71.01 \%)$ & $<0.01$ \\
\hline Albumin $<35 \mathrm{~g} / \mathrm{L}$ & $139(45.72 \%)$ & $95(68.84 \%)$ & $<0.01$ \\
\hline ALT/AST abnormal & 99 (32.57\%) & $42(30.43 \%)$ & 0.66 \\
\hline Creatinine $>73 \mu \mathrm{mol} / \mathrm{L}$ & 60 (19.74\%) & $28(20.29 \%)$ & 0.89 \\
\hline $\mathrm{BUN},>8 \mathrm{mmol} / \mathrm{L}$ & 87 (28.62\%) & $30(21.74 \%)$ & 0.13 \\
\hline $\mathrm{LDH}>250 \mathrm{U} / \mathrm{L}$ & $42(13.82 \%)$ & $60(43 / 48 \%)$ & $<0.01$ \\
\hline Creatine kinase $>195 \mathrm{U} / \mathrm{L}$ & $21(6.91 \%)$ & $6(4.35 \%)$ & 0.3 \\
\hline Troponin-I >0.4 ug/L & $49(16.12 \%)$ & $25(18.12 \%)$ & 0.6 \\
\hline $\begin{array}{l}\text { Patients tested for } \\
\text { procalcitonin, no. }\end{array}$ & 31 & 117 & \\
\hline $\begin{array}{l}\text { Procalcitonin } \\
>0.05 \mathrm{ng} / \mathrm{mL}\end{array}$ & $13(41.94 \%)$ & 55 (47.01\%) & 0.61 \\
\hline
\end{tabular}

$P$-value indicates differences between COVID-19 and SN-CAP, $P<0.05$ was considered statistically significant. 
SARS-CoV-2, influenza A (H1N1), and influenza B virus. This retrospective study was approved by the ethics committee of Sichuan Provincial People's Hospital.

\section{Diagnostic Criteria and Disease Severity Grading Criteria}

According to the WHO guidance, the patients were divided into young age (18-44 years), middle age (45-19 years), and old age (>60 years) groups.

According to the fifth edition of the China Guidelines for the Diagnosis and Treatment Plan of COVID-19 Infection by the National Health Commission (Trial Version 5) (Lin and Li, 2020), the cases were classified into four types: (1) mild: with slight clinical symptoms but no imaging presentations of pneumonia; (2) moderate: with fever, respiratory symptoms, and imaging presentations of pneumonia; (3) severe: with any of the following: respiratory distress with $\mathrm{RR}>30$ time/min, oxygen saturation at rest $<93 \%$, or $\mathrm{PaO} 2 / \mathrm{FiO} 2<300 \mathrm{mmHg}$ (I mmHg $=0.133 \mathrm{kPa}$ ); (4) critically severe: with any of the following: respiratory failure needing mechanical ventilation, shock, or combination with other organ failure needing ICU intensive care. The mild type was not admitted to hospital, so we enrolled moderate, severe, and critically severe cases.
SN-CAP cases were diagnosed according to the American Thoracic Society/Infectious Diseases Society of America 2019 guideline (Metlay and Waterer, 2020) and divided into moderate and severe groups.

\section{Data Collection and Statistical Analysis}

Clinical symptoms, radiological features, and laboratory examination data were collected from patients' electronic medical records. The data were reviewed by three physicians.

Data analyses were performed by SPSS software (Version 23.0, IBM, China). Continuous variables were measured as mean (standard deviation, SD). Categorical data were measured as number (\%) and tested with Chi-Square test. One-way analysis of variance (ANOVA) was used to evaluate comparisons between the groups. $P<0.05$ was considered statistically significant.

\section{RESULT}

\section{Clinical Features in COVID-19 and SN-CAP}

We enrolled 304 patients infected with SARS-CoV-2 with a mean age of 61.5 years (SD, 13.3 years). The gender composition was 166 females and 138 males. Besides, we included 138 SNCAP patients who were negative for SARS-CoV-2; their gender

TABLE 2 | Laboratory results of COVID-19 and SN-CAP.

\begin{tabular}{|c|c|c|c|c|c|c|}
\hline mean (SD) & & $\begin{array}{l}\text { COVID-19 } \\
n=304\end{array}$ & \multicolumn{3}{|c|}{$\begin{array}{l}\text { SN-CAP } \\
n=138\end{array}$} & $P$-value \\
\hline White blood cell count, x109/L & & $6.47(3.05)$ & \multicolumn{3}{|c|}{$8.13(4.12)$} & $<0.01$ \\
\hline Lymphocyte count, x109/L & & $1.18(0.72)$ & \multicolumn{3}{|c|}{$1.21(0.69)$} & 0.7 \\
\hline Lymphocyte ratio, \% & & $20(11)$ & \multicolumn{3}{|c|}{$17(10)$} & $<0.01$ \\
\hline Neutrophil count, x109/L & & $4.82(3.04)$ & \multicolumn{3}{|c|}{$6.25(4.09)$} & $<0.01$ \\
\hline Platelet count, x109/L & & 204 (83) & \multicolumn{3}{|c|}{$199(83)$} & 0.52 \\
\hline C-Reactive protein, mg/L & & $45.6(64.4)$ & \multicolumn{3}{|c|}{$40.5(50.6)$} & 0.44 \\
\hline NLR, \% & & $6.75(11.25)$ & \multicolumn{3}{|c|}{8.55 (12.76) } & 0.12 \\
\hline PLR, \% & & 225 (162) & \multicolumn{3}{|c|}{$227(176)$} & 0.82 \\
\hline Albumin, g/L & & $34.04(4.68)$ & \multicolumn{3}{|c|}{$36.31(6.61)$} & 0.1 \\
\hline Troponin-I, ug/L & & $0.18(0.63)$ & \multicolumn{3}{|c|}{$0.21(0.42)$} & 0.73 \\
\hline Creatinine, $\mu \mathrm{mol} / \mathrm{L}$ & & $174(320)$ & \multicolumn{3}{|c|}{$149(297)$} & 0.43 \\
\hline BUN, 8 mmol/L & & $7.36(6.16)$ & \multicolumn{3}{|c|}{$6.73(5.6)$} & 0.31 \\
\hline \multirow[t]{2}{*}{ Disease severity } & \multicolumn{2}{|c|}{ Moderate } & \multirow[t]{2}{*}{$P^{*}$} & \multicolumn{2}{|c|}{ Severe (severe + critically severe) } & $P^{\star \star}$ \\
\hline & $\begin{array}{c}\text { COVID-19 } \\
n=140\end{array}$ & $\begin{array}{c}\text { SN-CAP } \\
n=97\end{array}$ & & $\begin{array}{c}\text { COVID-19 } \\
n=164\end{array}$ & $\begin{array}{c}\text { SN-CAP } \\
n=41\end{array}$ & \\
\hline White blood cell count, x109/L & $5.72(2.03)$ & $7.67(3.1)$ & $<0.01$ & $7.11(3.58)$ & $9.2(5.85)$ & $<0.01$ \\
\hline Lymphocyte count, x109/L & $1.44(0.6)$ & $1.27(0.65)$ & 0.04 & $0.96(0.75)$ & $1.06(0.75)$ & 0.43 \\
\hline Lymphocyte ratio, \% & $26.59(10.17)$ & $18(0.95)$ & $<0.01$ & 15.39 (9.82) & 13.85 (10.3) & 0.37 \\
\hline Neutrophil count, x109/L & $3.77(1.82)$ & $5.62(2.74)$ & $<0.01$ & $5.73(3.55)$ & $7.71(5.99)$ & $<0.01$ \\
\hline Platelet count, x109/L & $223(76)$ & $187(81)$ & 0.01 & $188(86)$ & $203(90)$ & 0.33 \\
\hline C-Reactive protein, mg/L & $16(30)$ & $34.88(43.25)$ & $<0.01$ & $67.75(73.93)$ & $53.4(63.1)$ & 0.26 \\
\hline NLR, \% & $3.1(2.41)$ & $6.42(8.14)$ & $<0.01$ & $11.66(27.66)$ & $13.6(19)$ & 0.67 \\
\hline PLR, \% & $181(97)$ & $193(120)$ & 0.42 & 262 (196) & $309(248)$ & 0.2 \\
\hline
\end{tabular}

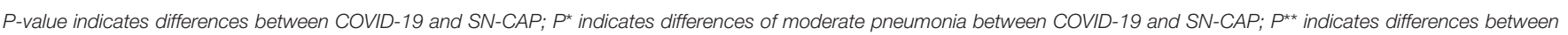
COVID-19 severe + critically severe group and SN-CAP severe group.

$P<0.05$ was considered statistically significant. 


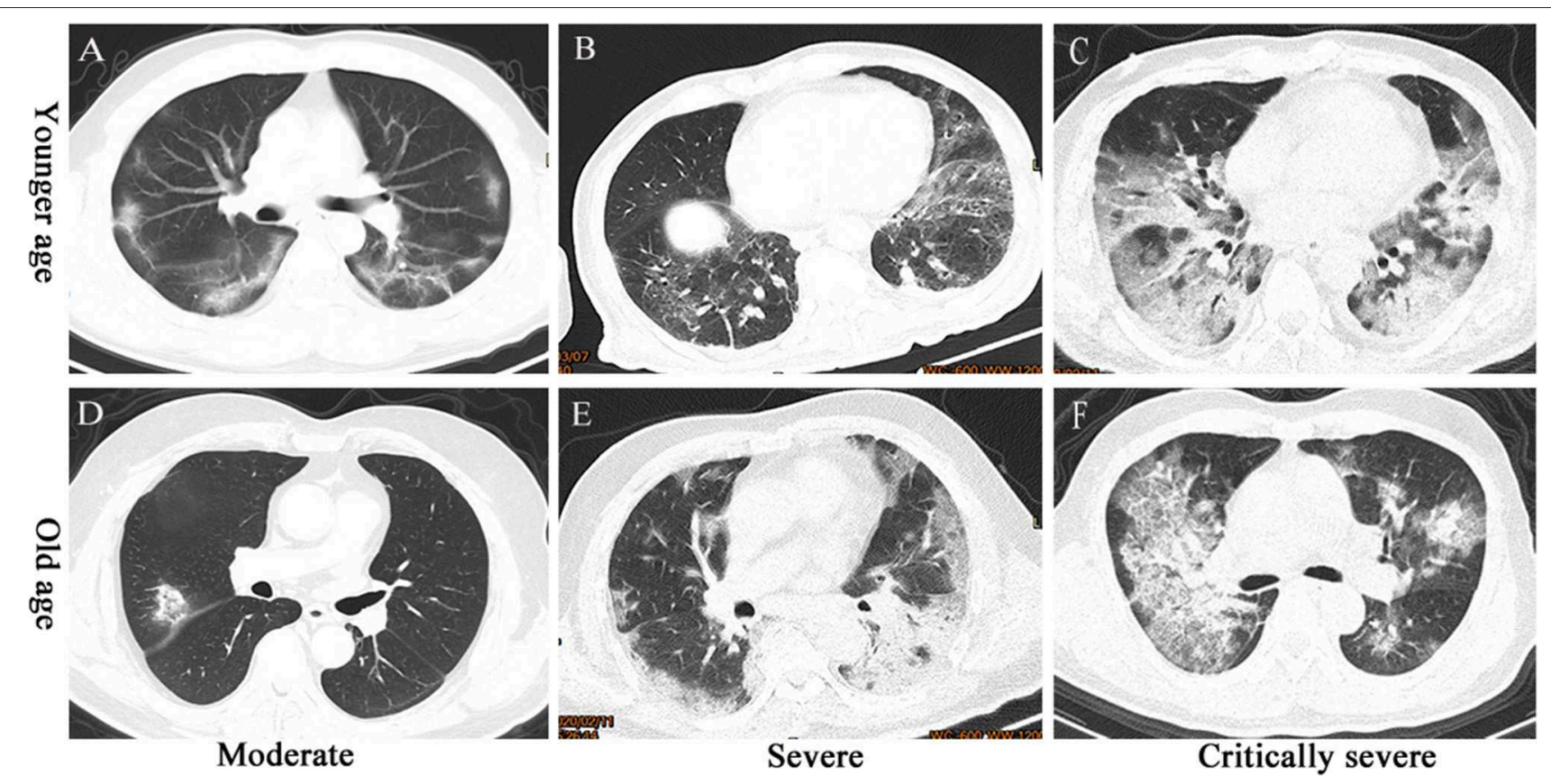

FIGURE 1 | CT imaging of COVID-19 patients. (A) Moderate-severity pneumonia in a 36-year-old man presenting as ground-glass opacity under the pleura in both the lungs. (B) Severe pneumonia in a 50-year-old man presenting as ground-glass opacity and large exudative shadows in both the lungs. (C) Critically severe pneumonia in a 58-year-old man presenting as large patches of exudative shadows in both lungs. (D) Moderate-severity pneumonia in a 63-year-old woman presenting as ground-glass opacity in the right upper lobe. (E) Severe pneumonia in a 78-year-old woman presenting as large exudative shadows in both lungs. (F) Critically severe pneumonia in a 69-year-old man presenting as large patches of ground-glass opacity and exudative shadows in both lungs.
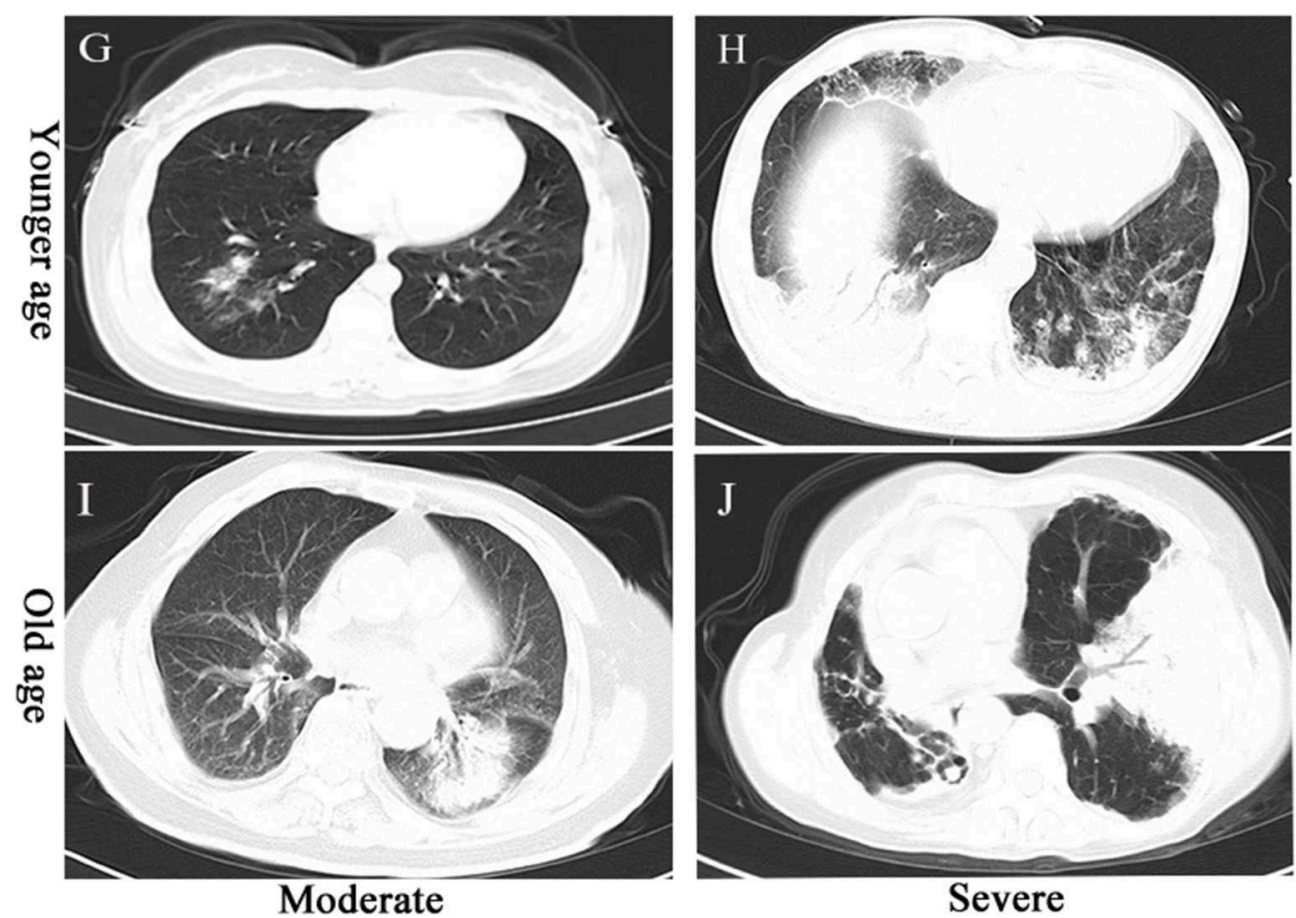

FIGURE 2 | CT imaging of SN-CAP patients. (G) Moderate-severity pneumonia in a 49-year-old woman presenting as patchy exudative shadows in the right upper lobe. (H) Severe pneumonia in a 50-year-old man presenting as large exudative shadows in both lungs. (I) Moderate-severity pneumonia in a 90-year-old man presenting as exudative shadows in the left lower lobe. (J) Severe pneumonia in an 80-year-old woman presenting as large exudative shadows in both lungs. 
TABLE 3 | Clinical characteristics of COVID-19 in different age ranges.

\begin{tabular}{|c|c|c|c|c|c|c|c|c|c|}
\hline \multirow[t]{2}{*}{ Age range } & \multicolumn{5}{|c|}{ Non-old (young and middle age), patient no. } & \multicolumn{4}{|c|}{ Old age, patient no. } \\
\hline & $\begin{array}{c}\text { Total } \\
n=137\end{array}$ & $\begin{array}{c}\text { Moderate } \\
n=77\end{array}$ & $\begin{array}{l}\text { Severe } \\
n=41\end{array}$ & $\begin{array}{c}\text { Critically } \\
\text { severe } \\
n=19\end{array}$ & $P$-Valve ${ }^{d}$ & $\begin{array}{c}\text { Total } \\
n=167\end{array}$ & $\begin{array}{c}\text { Moderate } \\
n=63\end{array}$ & $\begin{array}{l}\text { Severe } \\
n=73\end{array}$ & $\begin{array}{c}\text { Critically } \\
\text { severe } \\
n=31\end{array}$ \\
\hline Female & $72(52.55 \%)$ & $45(58.44 \%)$ & 19 (46.34\%) & $8(42.11 \%)$ & 0.52 & $94(56.29 \%)$ & $40(63.49 \%)$ & $42(57.53 \%)$ & $12(38.71 \%)$ \\
\hline Male & $65(47.44 \%)$ & $32(41.56 \%)$ & $22(53.66 \%)$ & $11(57.89 \%)$ & & $73(43.71 \%)$ & $23(36.51 \%)$ & $31(42.47 \%)$ & $19(61.29 \%)$ \\
\hline \multicolumn{10}{|c|}{ SIGNS AND SYMPTOMS AT ADMISSION } \\
\hline Fever & 77 (56.20\%) & $43(55.84 \%)$ & $28(68.29 \%)$ & $6(31.58 \%)$ & 0.91 & $95(56.89 \%)$ & $32(50.79 \%)$ & $52(71.23 \%)$ & $11(35.48 \%)$ \\
\hline Cough & $58(42.34 \%)$ & $36(46.75 \%)$ & $17(41.46 \%)$ & $5(26.31 \%)$ & 0.58 & $76(45.51 \%)$ & 27 (42.86\%) & 39 (53.42\%) & 10 (32.26\%) \\
\hline Dyspnea & 9 (6.57\%) & $6(7.79 \%)$ & $2(4.88 \%)$ & 1 (5.26\%) & 0.11 & 20 (11.98\%) & 7 (11.11\%) & $8(10.96 \%)$ & $5(16.13 \%)$ \\
\hline Fatigue & 19 (13.87\%) & 11 (14.29\%) & 6 (14.63\%) & 2 (10.53\%) & 0.09 & 13 (7.78\%) & $4(6.35 \%)$ & 8 (10.96\%) & 1 (3.23\%) \\
\hline Chest distress & 10 (7.30\%) & 7 (9.09\%) & 1 (2.44\%) & 2 (10.53\%) & 0.75 & 14 (8.38\%) & 10 (15.87\%) & 2 (2.74\%) & 2 (6.45\%) \\
\hline Expectoration & $6(4.38 \%)$ & 2 (2.60\%) & 3 (7.32\%) & 1 (5.26\%) & 0.33 & $4(2.40 \%)$ & 1 (1.59\%) & 2 (2.74\%) & 1 (3.23\%) \\
\hline Sore throat & 3 (2.19\%) & 1 (1.30\%) & $2(4.88 \%)$ & 0 & 0.5 & $2(1.20 \%)$ & 1 (1.59\%) & $1(1.37 \%)$ & 0 \\
\hline Diarrhea & $2(1.46 \%)$ & 1 (1.30\%) & 1 (2.44\%) & 0 & 0.82 & $3(1.80 \%)$ & 0 & 3 (4.11\%) & 0 \\
\hline Asymptomatic & 19 (13.87\%) & 13 (16.88\%) & $6(14.63 \%)$ & 0 & 0.62 & 20 (11.98\%) & 10 (15.87\%) & 10 (13.70\%) & 0 \\
\hline \multicolumn{10}{|c|}{ CHRONIC MEDICAL ILLNESS } \\
\hline Hypertension & 18 (13.14\%) & $5(6.49 \%)$ & $11(6.83 \%)$ & $2(10.53 \%)$ & $<0.01$ & $65(38.92 \%)$ & $21(33.33 \%)$ & $34(46.58 \%)$ & $10(32.26 \%)$ \\
\hline CAD & $4(2.92 \%)$ & $1(1.30 \%)$ & $3(7.32 \%)$ & 0 & 0.01 & $17(10.18 \%)$ & $5(7.94 \%)$ & $10(13.70 \%)$ & $2(6.45 \%)$ \\
\hline Diabetes & $7(5.11 \%)$ & $3(3.90 \%)$ & $2(4.88 \%)$ & $2(10.53 \%)$ & $<0.01$ & $33(19.76 \%)$ & $11(17.46 \%)$ & $16(21.92 \%)$ & $6(19.35 \%)$ \\
\hline COPD & $1(0.73 \%)$ & $1(1.30 \%)$ & 0 & 0 & 0.1 & $6(3.59 \%)$ & $1(1.59 \%)$ & $4(5.48 \%)$ & $1(3.23 \%)$ \\
\hline Renal failure & $12(8.76 \%)$ & $1(1.30 \%)$ & 9 (21.95\%) & $2(10.53 \%)$ & 0.95 & 15 (8.98\%) & $1(1.59 \%)$ & $11(15.07 \%)$ & $3(9.68 \%)$ \\
\hline Malignancy & $2(1.46 \%)$ & $1(1.30 \%)$ & 1 (2.44\%) & 0 & 0.45 & 1 (0.60\%) & 0 & 1 (1.37\%) & 0 \\
\hline
\end{tabular}

$P$-value ${ }^{d}$ indicates differences between old age and non-old age COVID-19 patients, $P<0.05$ was considered statistically significant.

ratio was 56 females to 82 males. The two study groups had no statistically significant difference in age distribution. At admission, both COVID-19 and SN-CAP patients presented with fever, cough, dyspnea, fatigue, chest distress, expectoration, sore throat, and diarrhea. However, COVID-19 patients had a higher rate of fever and dyspnea and a lower rate of expectoration than SN-CAP patients. Notably, 39 COVID-19 patients and $6 \mathrm{SN}$ CAP patients were asymptomatic at admission. According to the guidance, 140 COVID-19 patients were classified into the moderate group, 123 into the severe group, and 41 into the critically severe group; $97 \mathrm{SN}$-CAP patients were graded to the moderate group, and 41 to the severe group. We observed hypertension, coronary arteriosclerosis disease (CAD), diabetes, chronic obstructive pulmonary disease (COPD), renal failure, and malignant tumor as the most common complications in both groups. However, COVID-19 patients had a lower rate of COPD and malignancy than SN-CAP patients (Table 1).

Comparison of the blood cell and biochemistry results of the COVID-19 and SN-CAP patients revealed significance differences in the WBC count, lymphocyte ratio, and neutrophil count. In the subgroup analysis, we compared the COVID19 and SN-CAP patients according to disease severity. In the moderate group comparison, the SN-CAP showed significantly elevated WBC count, neutrophil count, CRP, neutrophil to lymphocyte ratio (NLR), and platelet to lymphocyte ratio (PLR) but a decreased lymphocyte ratio. The severe and critically severe groups of COVID-19 were amalgamated into one group when compared with the SN-CAP severe group, and the results showed significance differences in the WBC count and neutrophil count (Table 2). The blood cell counts of the young age and middle age groups did not differ across the two study populations. However, we observed significant differences in the WBC count, lymphocyte ratio, and neutrophil count in the old age group (Supplementary Table 1).

Computed tomography (CT) imaging of COVID-19 patients showed mainly patchy ground-glass opacities under the pleura. These patchy shadows did not differ across the various age ranges. The severe and critically severe groups showed larger patchy and exudative shadows than the moderate patient group (Figure 1). Among SN-CAP patients, we observed patchy exudation in the lung lobes, and these features were not significantly different across the age ranges. The severe groups showed larger exudative shadows than the moderate group (Figure 2).

\section{Subgroup Comparisons of Clinical Features in COVID-19}

The age range composition of COVID-19 was 43 young age, 88 middle age, and 173 old age patients. The young and middle age patients were amalgamated into one group when compared with the old age patients. Symptoms at admission did not differ across the various age ranges; however, the old age individuals had more chronic diseases (Table 3).

The COVID-19 patients registered declines in lymphocyte count, lymphocyte ratio, and platelet count. (Table 4). We did not find any significant difference in blood cell count between young age, middle age, and old age patients (Supplementary Table 2), 
TABLE 4 | Laboratory results of COVID-19.

\begin{tabular}{|c|c|c|c|c|c|c|}
\hline & $\begin{array}{c}\text { Moderate } \\
n=140\end{array}$ & $\begin{array}{l}\text { Severe } \\
n=123\end{array}$ & $\begin{array}{l}\text { Critically severe } \\
\qquad n=41\end{array}$ & $P$-value ${ }^{a}$ & $P$-value ${ }^{\mathrm{b}}$ & $P$-value ${ }^{c}$ \\
\hline Age, mean (SD), y & $55.9(14.4)$ & $63.8(13.9)$ & $65.2(12.7)$ & 0.06 & 0.05 & 0.06 \\
\hline Female & 85 & 65 & 16 & 0.25 & 0.01 & 0.2 \\
\hline Male & 55 & 58 & 25 & & & \\
\hline WBC, x109/L & $5.72(2.03)$ & $6.47(2.8)$ & $8.97(4.89)$ & 0.03 & $<0.01$ & $<0.01$ \\
\hline Lymphocyte, x109/L & $1.44(0.6)$ & $1.05(0.8)$ & $0.68(0.44)$ & $<0.01$ & $<0.01$ & $<0.01$ \\
\hline Lymphocyte ratio, \% & $26.59(10.17)$ & 17.23 (8.64) & $10.55(11.44)$ & $<0.01$ & $<0.01$ & $<0.01$ \\
\hline Neutrophil, x109/L & $3.77(1.82)$ & $5.02(2.7)$ & $7.86(4.82)$ & $<0.01$ & $<0.01$ & $<0.01$ \\
\hline Platelet, x109/L & $223(76)$ & $193(85)$ & $173(91)$ & $<0.01$ & $<0.01$ & 0.16 \\
\hline CRP, mg/L & $16(30)$ & $46.2(56.5)$ & $114.8(87.94)$ & $<0.01$ & $<0.01$ & $<0.01$ \\
\hline NLR, \% & $3.1(2.41)$ & $6.92(6.3)$ & $19.47(24.35)$ & $<0.01$ & $<0.01$ & $<0.01$ \\
\hline PLR, \% & $181(97)$ & 234 (169) & 346 (243) & $<0.01$ & $<0.01$ & $<0.01$ \\
\hline Albumin, g/L & $35.73(3.96)$ & 33.68 (4.81) & $29.48(3.14)$ & 0.002 & $<0.001$ & 0.553 \\
\hline Troponin-I, ug/L & $0.058(0.17)$ & $0.07(0.11)$ & 0.77 (1.35) & 0.921 & $<0.001$ & 0.475 \\
\hline Creatinine, umol/L & $51.31(36.62)$ & 226.39 (384.2) & 249.2 (348) & $<0.001$ & $<0.001$ & 0.317 \\
\hline BUN, mmol/L & $5.48(2.9)$ & $8.17(7.12)$ & 11.32 (8.29) & $<0.001$ & $<0.001$ & 0.834 \\
\hline
\end{tabular}

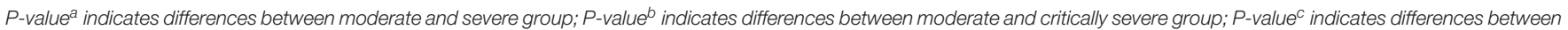
severe and critically severe group; $P<0.05$ was considered statistically significant.

but a significant disparity was evident between the moderate, severe, and critically severe groups. Compared with the moderate group, the severe and critically severe groups showed significant rises in WBC count, neutrophil count, NLR, PLR, CRP, lactate dehydrogenase (LDH), troponin-I, and creatinine and significant decreases in lymphocytes, lymphocyte ratio, platelets, and albumin (Table 4).

In the young age group, we did not observe any significant difference in blood cell data across the moderate, severe, and critically severe groups. However, the blood cell data (WBC, lymphocyte, lymphocyte ratio, neutrophil, NLR, PLR, CRP) for the middle and old age groups differed significantly across the three categories of disease severity (Table 5).

Regarding the biochemistry data, the COVID-19 patients had a rise in C-reactive protein (CRP) levels. The young, middle, and old age COVID-19 patients had no significant difference in CRP levels. However, in terms of disease severity, the severe and critically severe patient groups had higher CRP levels than the moderate group. When disease severity was stratified according to age, we did not find a significant difference in CRP levels in the young patients. This relationship changed in the middle and old age groups, in which CRP levels differed significantly.

\section{DISCUSSION}

COVID-19 is a highly contagious disease that poses a serious threat to public health across the globe (Feng et al., 2020; Wang D. et al., 2020; Wu and McGoogan, 2020). Despite major investment, there is still a shortage of medical staff and resources. In order to optimize medical resources and ensure maximum patient care, it is essential to recognize the disease as distinct from CAP and identify the severe patients. Older adults had a higher severity of COVID-19 due to the low immunity status associated with the aging process (Applegate and Ouslander, 2020). Immunity is an essential factor for disease development and severity. These facts informed the stratification of the patients into young age, middle age, and old age groups for further comparison. SN-CAP had more symptoms of expectoration and higher WBC and neutrophil counts than COVID-19 due to increased infiltration of inflammation cells, injury of alveolar walls, and high inflammatory exudation in the alveoli. Pathogens of CAP mainly include bacteria, mycoplasma, virus, and fungus; however, bacterial infection accounts for more than half (Metlay and Waterer, 2020). Elevated WBC count, neutrophil count, and CRP level are the common inflammatory indicators in bacterial infection. According to disease severity, both the moderate and severe groups showed significant increases in many inflammatory indicators in SN-CAP. Patients of the two groups had no significant difference in chronic disease status, except COPD, and malignancy. This may be caused by the case enrollment: the SN-CAP patients were mainly enrolled from the respiratory department in Sichuan Provincial People's Hospital, and COPD and pulmonary tumor are important respiratory diseases in the department. Furthermore, the morbidity of COPD is high in Sichuan province, and the incidence of SN-CAP in these patients is higher in winter and spring.

CT imaging of COVID-19 patients showed patchy groundglass opacities under pleura, and these findings are consistent with the findings of previous studies (Wang D. et al., 2020; $\mathrm{Xu} \mathrm{Y.} \mathrm{H.} \mathrm{et} \mathrm{al.,} \mathrm{2020).} \mathrm{The} \mathrm{CT} \mathrm{presentation} \mathrm{in} \mathrm{the} \mathrm{severe} \mathrm{and}$ critically severe groups showed larger patchy and exudative shadows, which represent the pathological alterations of SARSCoV-2 or/and bacteria (Wang D. et al., 2020). The CT imaging of SN-CAP showed patchy high-density shadows, which were caused by inflammatory exudation. CT imaging presentation is an important indicator for the disease severity of both COVID-19 and SN-CAP. 
TABLE 5 | Blood cell analysis of COVID-19.

\begin{tabular}{|c|c|c|c|c|c|c|}
\hline & Moderate & Severe & Critically severe & $P$-value ${ }^{a}$ & $P$-value ${ }^{b}$ & $P$-value ${ }^{c}$ \\
\hline \multicolumn{7}{|l|}{ YOUNG AGE: 18-44 } \\
\hline Patient no. (43) & 30 & 10 & 3 & & & \\
\hline WBC, x109/L & $6.19(2.2)$ & $6.49(2.79)$ & $6.05(2.67)$ & 0.4 & 0.91 & 0.57 \\
\hline Lymphocyte, x109/L & $1.55(0.5)$ & $1.05(0.8)$ & $0.79(0.44)$ & 0.22 & 0.03 & 0.18 \\
\hline Lymphocyte ratio, \% & $26.42(7.8)$ & $16.98(8.69)$ & $16.5(14.82)$ & 0.03 & 0.06 & 0.63 \\
\hline Neutrophil, x109/L & $4.11(1.76)$ & $5.02(2.69)$ & $4.79(2.62)$ & 0.16 & 0.53 & 0.84 \\
\hline Platelet, x109/L & $238(74)$ & $194(84)$ & $120(36)$ & $<0.05$ & 0.01 & 0.22 \\
\hline CRP, mg/L & $12(22.8)$ & $67.77(56.75)$ & $64.84(71.12)$ & 0.27 & 0.1 & 0.08 \\
\hline NLR, \% & $2.81(1.33)$ & 9.08 (28.29) & $9.51(9.8)$ & 0.04 & $<0.01$ & 0.03 \\
\hline PLR, \% & $165(58)$ & 234 (170) & $182(82)$ & 0.89 & 0.74 & 0.82 \\
\hline \multicolumn{7}{|l|}{ MIDDLE AGE: 45-59 } \\
\hline Patient no. (88) & 44 & 33 & 11 & & & \\
\hline WBC, x109/L & $5.38(2.3)$ & $7.19(3.17)$ & $8.27(4.96)$ & 0.01 & $<0.01$ & 0.31 \\
\hline Lymphocyte, x109/L & $1.31(0.55)$ & $0.99(0.37)$ & $0.67(0.54)$ & $<0.01$ & $<0.01$ & 0.07 \\
\hline Lymphocyte ratio, \% & $26.16(11.62)$ & 15.05 (7.64) & $10.44(10.24)$ & $<0.01$ & $<0.01$ & 0.19 \\
\hline Neutrophil, x109/L & $3.6(2.2)$ & 5.64 (3.09) & 7.37 (4.63) & $<0.01$ & $<0.01$ & 0.09 \\
\hline Platelet, x109/L & 225 (86) & 214 (103) & $143(53)$ & 0.6 & $<0.01$ & 0.03 \\
\hline CRP, mg/L & $19.22(40.53)$ & $67.58(82.27)$ & $105(96)$ & 0.01 & $<0.01$ & 0.14 \\
\hline NLR, \% & $3.34(2.82)$ & $6.97(6.1)$ & $14.98(8.74)$ & $<0.01$ & $<0.01$ & $<0.01$ \\
\hline PLR, \% & 198 (110) & 245 (139) & 300 (185) & 0.13 & 0.02 & 0.23 \\
\hline \multicolumn{7}{|l|}{ OLD AGE: $\geq 60$} \\
\hline Patient no. (173) & 66 & 80 & 27 & & & \\
\hline WBC, x109/L & $5.74(1.74)$ & $6.32(2.75)$ & $9.57(5.02)$ & 0.4 & $<0.01$ & $<0.01$ \\
\hline Lymphocyte, x109/L & $1.47(0.67)$ & $1.09(1.24)$ & $0.67(0.41)$ & $<0.01$ & $<0.01$ & 0.03 \\
\hline Lymphocyte ratio, \% & $11.24(14.44)$ & $16.73(8.28)$ & $9,93(11.81)$ & $<0.01$ & $<0.01$ & $<0.01$ \\
\hline Neutrophil, x109/L & $3.72(1.58)$ & $4.97(2.65)$ & $8.4(5.05)$ & 0.03 & $<0.01$ & $<0.01$ \\
\hline Platelet, x109/L & $215(71)$ & $190(81)$ & 191 (102) & 0.03 & 0.19 & 0.81 \\
\hline CRP, mg/L & $16.3(26.07)$ & $44.69(42.17)$ & 125 (87) & $<0.01$ & $<0.01$ & $<0.01$ \\
\hline NLR, \% & $3.25(2.6)$ & $20.81(34.75)$ & $22.41(29.1)$ & 0.1 & $<0.01$ & 0.04 \\
\hline PLR, \% & 178 (101) & 245 (187) & $383(267)$ & 0.04 & $<0.01$ & $<0.01$ \\
\hline
\end{tabular}

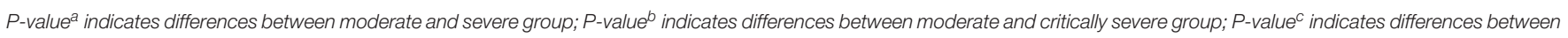
severe and critically severe group; $P<0.05$ was considered statistically significant.

According to the China CDC guidelines, COVID-19 was divided into mild, moderate, severe, and critically severe. In this study, we included patients with signs of pneumonia in CT imaging, and since mild cases have no pneumonia presentation, they were excluded. The blood count results of 140 moderate, 123 severe, and 41 critically severe COVID-19 patients were analyzed. The age showed no significant difference in these groups. Consistent with previous research, COVID-19 patients mainly presented with fever, cough, fatigue, and dyspnea (Yang et al., 2020; Zhang et al., 2020). Older COVID-19 individuals had more chronic diseases and significantly elevated WBC, neutrophil, and CRP levels.

Compared to the moderate group, the severe and critically severe groups had increased levels of WBC, neutrophil, platelets, CRP, NLR, PLR, BUN, LDH, troponin-I, and creatinine and decreased lymphocyte ratios and levels of lymphocytes and albumin. These abnormal findings for blood cells and biochemistry suggest that the virus infection may induce liver, kidney, and myocardial injury in addition to the destruction of immune cells (Wang C. et al., 2020). The study results are consistent with autopsy findings of COVID-19 patients, which have shown lung, liver, and myocardium injury. On histological examination, the lung tissue was characterized by inflammatory infiltrates and dominated by lymphocytes, while liver biopsy revealed microvesicular steatosis due to the direct effect of the virus or drugs. A few monocytes infiltrated the myocardium, causing pathological changes (Xu Z. et al., 2020). Possibly, the virus mainly induces inflammation in the lungs, as do SARS and MERS (Ding et al., 2003; Ng et al., 2016). In the young age group, we did not observe any significant difference in blood cell metrics across the moderate, severe, and critically severe groups. However, the values of the blood cell metrics (WBC, lymphocyte, lymphocyte ratio, neutrophil, NLR, PLR, and CRP) for the middle and old age groups differed significantly across the three categories of disease severity. This may be caused by the co-infection of bacteria in the middle and old age groups. 
Viruses interfere with the immune system of patients and then induce secondary bacterial infection (Du Toit, 2020). It had been reported that bacterial infection is common in H1N1 infection (Milosevic et al., 2013). Because of the low immunity, the middle age and old age individuals are more susceptible to secondary bacterial infection, especially patients with chronic disease.

Previous studies showed that lymphopenia is a typical feature in COVID-19 patients and might be associated with disease severity (Chan et al., 2020). In this study, nearly 30-40\% of patients had decreased levels of lymphocytes and 50\% had a decline in the lymphocyte ratio. Notably, lymphopenia was more remarkable in the severe and critically severe groups. The study findings, therefore, corroborated previous research that has identified lymphopenia as an important indicator of COVID-19 severity. Despite the lymphopenia status in the severe and critically severe groups, the WBC levels were elevated, possibly due to secondary bacterial infections ((Chen et al., 2020). Destruction of the immune cells by SARS-CoV-2 virus makes the patients vulnerable to secondary bacterial infections. Additional indicators include the NLR and PLR, which are sensitive biomarkers for both natural and acquired immune responses (Polat et al., 2014; Kartal and Kartal, 2017). They are considered indicators of infection and systemic inflammation (Korkmaz et al., 2015). In this study, both NLR and PLR were statistically different across the moderate, severe, and critically severe groups. The NLR and PLR values were closely correlated with the severity of the disease.

This study has several limitations. First, due to a shortage of medical staff and resources, sputum culture is impossible in Wuhan Red Cross Hospital, and thus there is no evidence with which to identify secondary bacterial infections. Second, COVID-19 patients were enrolled from Wuhan Red Cross Hospital, and SN-CAP patients were from Sichuan Provincial People's Hospital; multi-center studies with more patients are needed for further evaluation.

In summary, COVID-19 is a highly infectious disease that affects people across all age groups. Patients with COVID-19 had lower WBC and neutrophil levels than those with SN-CAP. The older adults with chronic diseases were more susceptible to severe and critically severe infections. CT imaging presentation,

\section{REFERENCES}

Applegate, W. B., and Ouslander, J.G. (2020). COVID-19 presents high risk to older persons. J Am. Geriatr. Soc. 68:681. doi: 10.1111/jgs.16426

Chan, J. F. W., Yuan, S., Kok, K. H., To, K. K. W., Chu, H., Yang, J., et al. (2020). A familial cluster of pneumonia associated with the 2019 novel coronavirus indicating person-to-person transmission: a study of a family cluster. Lancet 395, 514-523. doi: 10.1016/S0140-6736(20) 30154-9

Chen, N., Zhou, M., Dong, X., Qu, J., Gong, F., Han, Y., et al. (2020). Epidemiological and clinical characteristics of 99 cases of 2019 novel coronavirus pneumonia in Wuhan, China: a descriptive study. Lancet 395, 507-513. doi: 10.1016/S0140-6736(20)30211-7

Ding, Y., Wang, H., Shen, H., Li, Z., Geng, J., Han, H., et al. (2003). The clinical pathology of severe acute respiratory syndrome (SARS): a report from China. J. Pathol. 200, 282-289. doi: 10.1002/path.1440 lymphopenia, CRP, NLR, and PLR are significant indicators for severity grading of COVID-19.

\section{DATA AVAILABILITY STATEMENT}

The original contributions presented in the study are included in the article files; further inquiries can be directed to the corresponding authors.

\section{ETHICS STATEMENT}

The studies involving human participants were reviewed and approved by Ethics committee of Sichuan Provincial People's Hospital. Written informed consent for participation was not required for this study in accordance with the national legislation and the institutional requirements.

\section{AUTHOR CONTRIBUTIONS}

SG, YZ, and YH collected data. SG and QZ contributed to statistical analyses. DL, YZ, and JF analyzed CT images. SG and MX edited tables. SG and YH edited the manuscript. YZ and $\mathrm{XL}$ reviewed the manuscript. YZ and JF did their best to treat COVID-19 patients in Wuhan Red Cross Hospital. They fought for 2 months until the last patient was discharged from the hospital. All authors contributed to the article and approved the submitted version.

\section{FUNDING}

This work was funded by Grant 81700044 from the National Natural Science Foundation of China to SG. The fund had no role in study design, data collection and analysis, decision to publish, or preparation of the manuscript.

\section{SUPPLEMENTARY MATERIAL}

The Supplementary Material for this article can be found online at: https://www.frontiersin.org/articles/10.3389/fcimb. 2020.00322/full\#supplementary-material
Du Toit, A. (2020). Measles increases the risk of other infections. Nat. Rev. Microbiol. 18:2. doi: 10.1038/s41579-019-0301-7

Feng, Z., Yu, Q., Yao, S., Luo, L., Duan, J., Yan, Z., et al. (2020). Early prediction of disease progression in 2019 novel coronavirus pneumonia patients outside Wuhan with CT and clinical characteristics. medRxiv [preprint]. doi: 10.1101/2020.02.19.20025296

Huang, C., Wang, Y., Li, X., Ren, L., Zhao, J., Hu, Y., et al. (2020). Clinical features of patients infected with 2019 novel coronavirus in Wuhan, China. Lancet395, 497-506. doi: 10.1016/S0140-6736(20)30183-5

Jin, Y. H., Cai, L., Cheng, Z. S., Cheng, H., Deng, T., Fan, Y. P., et al. (2020). A rapid advice guideline for the diagnosis and treatment of 2019 novel coronavirus (2019-nCoV) infected pneumonia (standard version). Mil. Med. Res. 7:4. doi: 10.1186/s40779-020-0233-6

Kartal, O., and Kartal, A. T. (2017). Value of neutrophil to lymphocyte and platelet to lymphocyte ratios in pneumonia. Bratisl. Lek. Listy. 118, 513-516. doi: 10.4149/BLL_2017_099 
Korkmaz, M., Korkmaz, H., Küçüker, F., Ayyildiz, S. N., and Çankaya, S. (2015). Evaluation of the association of sleep apnearelated systemic inflammation with CRP, ESR, and neutrophil-tolymphocyte ratio. Med. Sci. Monit. 21, 477-481. doi: 10.12659/MSM.8 93175

Li, Q., Guan, X., Wu, P., Wang, X., Zhou, L., Tong, Y., et al. (2020). Early transmission dynamics in Wuhan, China, of novel coronavirus-infected pneumonia. N. Engl. J. Med. 382, 1199-1207. doi: 10.1056/NEJMoa20 01316

Lin, L., and Li, T. S. (2020). Interpretation of "guidelines for the diagnosis and treatment of novel coronavirus (2019-ncov) infection by the national health commission (trial version 5)". Zhonghua. YiXue. ZaZhi. 100:E001. doi: 10.3760/cma.j.issn.0376-2491.2020.0001

Metlay, J. P., and Waterer, G. W. (2020). Update in adult communityacquired pneumonia. Curr. Opin. Pulm. Med. 26, 203-207. doi: 10.1097/MCP.0000000000000671

Milosevic, I., Korac, M., Zerjav, S., Aleksandar, U., Lidija, L., Branko, M., et al. (2013). Non-specific inflammatory parameters in patients with pandemic H1N1 influenza. Biomed. Pharmacot. 67, 218-220. doi: 10.1016/j.biopha.2012.11.001

Ng, D. L., Al Hosani, F., Keating, M. K., Gerber, S. I., Jones, T. L., Metcalfe, M. G., et al. (2016). Clinicopathologic, immunohistochemical, and ultrastructural findings of a fatal case of middle east respiratory syndrome coronavirus infection in the United Arab Emirates, April 2014. Am. J. Pathol. 186, 652-658. doi: 10.1016/j.ajpath.2015.10.024

Polat, N., Yildiz, A., Yuksel, M., Bilik, M. Z., Aydin, M., Acet, H., et al. (2014). Association of neutrophil-lymphocyte ratio with the presence and severity of rheumatic mitral valve stenosis. Clin. Appl. Thromb. Hemost. 20, 793-798. doi: $10.1177 / 1076029613514131$

She, J., Jiang, J., Ye, L., Hu, L., Bai, C., and Song, Y. (2020). 2019 novel coronavirus of pneumonia in Wuhan, China: emerging attack and management strategies. Clin. Transl. Med. 9, 1-7. doi: 10.1186/s40169-020-0 0271-z

Shi, F., Xia, L., Shan, F., Wu, D., Wei, Y., Yuan, H., et al. (2020). Large-scale screening of covid-19 from community acquired pneumonia using infection size-aware classification. arXiv. 2003.09860.

Wang, C., Forst, C. V., Chou, T. W., Geber, A., Wang, M., Hamou, W., et al. (2020). Cell-to-cell variation in defective virus expression and effects on host responses during influenza virus infection. mBio. 11:e02880-19. doi: $10.1128 / \mathrm{mBio} .02880-19$

Wang, D., Hu, B., Hu, C., Zhu, F., Liu, X., Zhang, J., et al. (2020). Clinical characteristics of 138 hospitalized patients with 2019 novel coronavirus-infected pneumonia in Wuhan, China. JAMA. 323:1061. doi: $10.1001 /$ jama.2020.1585
World Health Organization (2020a). Clinical Management of Severe Acute Respiratory Infection When Novel Coronavirus ( $n \mathrm{CoV}$ ) Infection is Suspected: Interim Guidance. Available online at: https://www.who.int/docs/defaultsource/coronaviruse/clinical-management- of-novel-cov.pdf (accessed January 20, 2020)

World Health Organization (2020b). Coronavirus. Available online at: https://www. who.int/health-topics/coronavirus (accessed January 19, 2020).

Wu, Z., and McGoogan, J.M. (2020). Characteristics of and important lessons from the coronavirus disease 2019 (COVID-19) outbreak in China: summary of a report of 72314 cases from the Chinese center for disease control and prevention. JAMA. 323, 1239-1242. doi: 10.1001/jama.2020.2648

Xu, Y. H., Dong, J. H., An, W. M., Lv, X. Y., Yin, X. P., Zhang, J. Z., et al. (2020). Clinical and computed tomographic imaging features of Novel Coronavirus Pneumonia caused by SARS-CoV-2. J Infect. 80, 394-400. doi: 10.1016/j.jinf.2020.02.017

Xu, Z., Shi, L., Wang, Y., Zhang, J., Huang, L., Zhang, C., et al. (2020). Pathological findings of COVID-19 associated with acute respiratory distress syndrome. Lancet. Respir. Med. 8, 420-422. doi: 10.1016/S2213-2600(20)30076-X

Yang, X., Yu, Y., Xu, J., Shu, H., Liu, H., Wu, Y., et al. (2020). Clinical course and outcomes of critically ill patients with SARS-CoV-2 pneumonia in Wuhan, China: a single-centered, retrospective, observational study. Lancet. Respir. Med. 8, 475-481. doi: 10.1016/S2213-2600(20)30079-5

Zhang, B., Zhou, X., Qiu, Y., Feng, F., Feng, J., Jia, Y., et al. (2020). Clinical characteristics of 82 death cases with COVID-19. medRxiv [preprint]. doi: 10.1101/2020.02.26.20028191

Zhao, D., Yao, F. F., Wang, L. J., Zheng, L., Gao, Y. J., Ye, J., et al. (2020). A comparative study on the clinical features of COVID-19 pneumonia to other pneumonias. Clin Infec Dis. doi: 10.1093/cid/ciaa247. [Epub ahead of print].

Zhu, N., Zhang, D., Wang, W., Li, X., Yang, B., Song, J., et al. (2020). A novel coronavirus from patients with pneumonia in China, 2019. N. Engl. J Med. 382, 727-733. doi: 10.1056/NEJMoa2001017

Conflict of Interest: The authors declare that the research was conducted in the absence of any commercial or financial relationships that could be construed as a potential conflict of interest.

Copyright $\odot 2020$ Zhou, Guo, He, Zuo, Liu, Xiao, Fan and Li. This is an open-access article distributed under the terms of the Creative Commons Attribution License (CC $B Y)$. The use, distribution or reproduction in other forums is permitted, provided the original author(s) and the copyright owner(s) are credited and that the original publication in this journal is cited, in accordance with accepted academic practice. No use, distribution or reproduction is permitted which does not comply with these terms. 